This manuscript has not been formally peer-reviewed. It has been reviewed by a small number of environmental and computer scientists informally and published on the blog BayesianWatch.org. Subsequent versions of this manuscript may have slightly different content. Please feel free to contact the author; he welcomes feedback. 


\title{
How Extreme Weather Events Are Attributed to Anthropogenic Global Warming
}

\author{
Kevin B Korb \\ School of Historical and Philosophical Studies, Faculty of Arts \\ The University of Melbourne, Parkville, Victoria 3010 Australia \\ kbkorb@gmail.com
}

Many politicians and media personalities continue to cast doubt on the idea that anthropogenic global warming (AGW) - the primary driver of current global climate change could possibly be behind the growing frequency and severity of extreme weather events the droughts, heatwaves, flooding, etc. that are every year breaking 100 year or greater historical records. This takes the form not just of a straightforward denial of climate change, but also of a more plausible denial of a connection between climate change and individual extreme events. Until ten or five years ago, many climate scientists themselves would have agreed with rejecting such a connection, and some journalists and politicians have followed them and continue following them, even when they have stopped leading anyone in that direction (see box below). Climate scientists have stopped agreeing with this, because in the meantime a new subdiscipline has been developed specifically for attributing extreme weather events to AGW or to natural variation, depending upon the specifics of the case. While it may suit the political preferences of some commentators to ignore this development, it is not in the general interest. Here I present a brief and simple introduction to the main ideas in current work on attributing individual events to global warming. (An even simpler introduction to attribution science, emphasizing legal liability, can be found in Colman, 2019.)

\section{Climate versus Weather}

It has become a commonplace to point out that weather is not climate: climate refers to a long-term pattern of weather, not individual events. Usually the point meant is that some hot, or cold, weather is not evidence for, or against, anthropogenic global warming or significant climate change. That, however, is not true. Long-term patterns influence short-term events, whether or not the short-term events are classified as "extreme". As one of the original researchers on weather attribution put it:

In practice, all we can ever observe directly is weather, meaning the actual trajectory of the system over the climate attractor during a limited period of time. Hence we can never be sure, with finite observations and imperfect models, of what the climate is or how it is changing. (Allen, 2003)

This actually describes the relation between theories (or models, or simulations) and evidence in science quite generally. Claims about the state of the climate are theoretical, rather than observational. Theoretical claims cannot be directly observed to be true or false; but they do give rise to predictions whose probabilities can be calculated and whose outcomes can be observed. The probabilities of those outcomes provide support for and 
against our theories. There is always some uncertainty, but that pertaining to earth's rotation around the sun, the disvalue of bleeding sick humans and the reality of AGW have been driven to near zero.

Certainly, larger and more frequent storms are one of the consequences that the climate models and climate scientists predict from global warming but you cannot attribute any particular storm to global warming, so let's be quite clear about that. And the same scientists would agree with that. - Australian PM Malcolm Turnbull, 2016

It is problematic to directly attribute individual weather events, such as the current heatwave, to climate change because extreme weather events do occur as a part of natural climate variability. - Climate Change Minister Greg Combet, 2013

Scientists and the Bureau of Meteorology have repeatedly warned that individual events, be they the record cold temperatures and snow of late 2012 or heatwaves should not be attributed to any particular source. - Opposition spokesman for environment, Greg Hunt, $\underline{2013}$

I don't think you can at all, at this stage, link individual events to [climate change]. Australian Minister for Resources, Matt Canavan, 2019

You can't blame individual weather events, such as the Queensland floods, on climate change. - Norelle Towie, journalist, 2011

Individual weather events may be too isolated to link directly to climate change. - Larry West, educational writer, 2017

The only special difficulty in understanding the relation between climate and weather lies in the high degree of variability in the weather; discerning the signal buried within the stochastic noise is non-trivial (aka "the detection problem"), which is one reason why climate science and data analysis should be relied upon instead of lay persons' "gut feels". Denialists often want to play this distinction both ways: when the weather is excessively hot, variability means there is no evidence of AGW; when the weather is excessively cold, that means AGW is not real.

What matters is what the overall trends are, and the overall trends include increasing numbers of new high temperatures being set and decreasing numbers of new low temperatures being set at like locations and seasons, worldwide. For example, that ratio is 2:1 in the US from 2000-2010 (Climate Nexus, 2019). Or more generally, we see this in the continuing phenomenon of the latest ten years including nine of the 10 hottest years globally on record (NOAA "Global Climate Report 2018").

The analogy with the arguments about tobacco and cancer is a strong one. For decades, 
tobacco companies claimed that since the connection between smoking and cancers is stochastic (probabilistic, uncertain), individual cases of cancer could never be attributed to smoking, so liability in individual cases could not be proven (aka "the attribution problem"). The tobacco companies lost that argument: specific means of causal attribution have been developed for smoking (e.g., "relative risk", which is closely related to the methods discussed below for weather attribution; O'Keefe et al., 2018). Likewise, there are now accepted methods of attributing weather events to global warming, which I will describe below.

Rejecting the connection between weather and climate, aside from often being an act of hypocrisy, implies a rejection of the connection between evidence and theory: ultimately, it leads to a rejection of science and scientific method.

Weather Severity Is Increasing

Logically before attributing extreme weather to human activity ("attribution") comes finding that extreme weather is occurring more frequently than is natural ("detection"). Denialism regarding AGW of course extends to denialism of such increasing frequency of weather extremes. There are two main kinds of evidence of the worsening of weather worldwide.

Direct evidence includes straightforward measurements of weather. For example, measurements of the worldwide average temperature anomalies (departures from the mean temperature over some range of years) themselves have the extreme feature of showing ever hotter years, as noted above (NOAA "Global Climate Report 2018"). Simple statistics will report many of these kinds of measurements as exceedingly unlikely on the "null hypothesis" that the climate isn't changing. More dramatic evidence comes in the form of increased frequency and intensity of flooding, droughts, etc. (IPCC AR5 WG2 Technical Summary 2014, Section A-1). There is considerable natural variability in such extremes, meaning there is some uncertainty about some types of extreme weather. The NOAA, for example, refuses to commit to there being any increased frequency or intensity of tropical storms; however, many other cases of extreme weather are clear and undisputed by scientists, as we shall see.

Indirect evidence includes claims and costs associated with insuring businesses, private properties and lives around the world. While the population size and the size of economies around the world have been increasing along with $\mathrm{CO} 2$ in the atmosphere - resulting in increased insurance exposure - the actual costs of natural disasters have increased at a rate greater than the simple economic increase would explain (see Figure 1). In consequence, for example, "many insurers are throwing out decades of outdated weather actuarial data and hiring teams of in-house climatologists, computer scientists and statisticians to redesign their risk models." (Hoffman, 2018). The excess increase in costs, i.e., that beyond the underlying increase in the value of infrastructure and goods, can be attributed to climate change, as can the excess increase (beyond inflation) in the rates charged by insurers. 


\section{Economic Losses (USB \$)}

Economic Losses (USB\$) - Five-Year Average

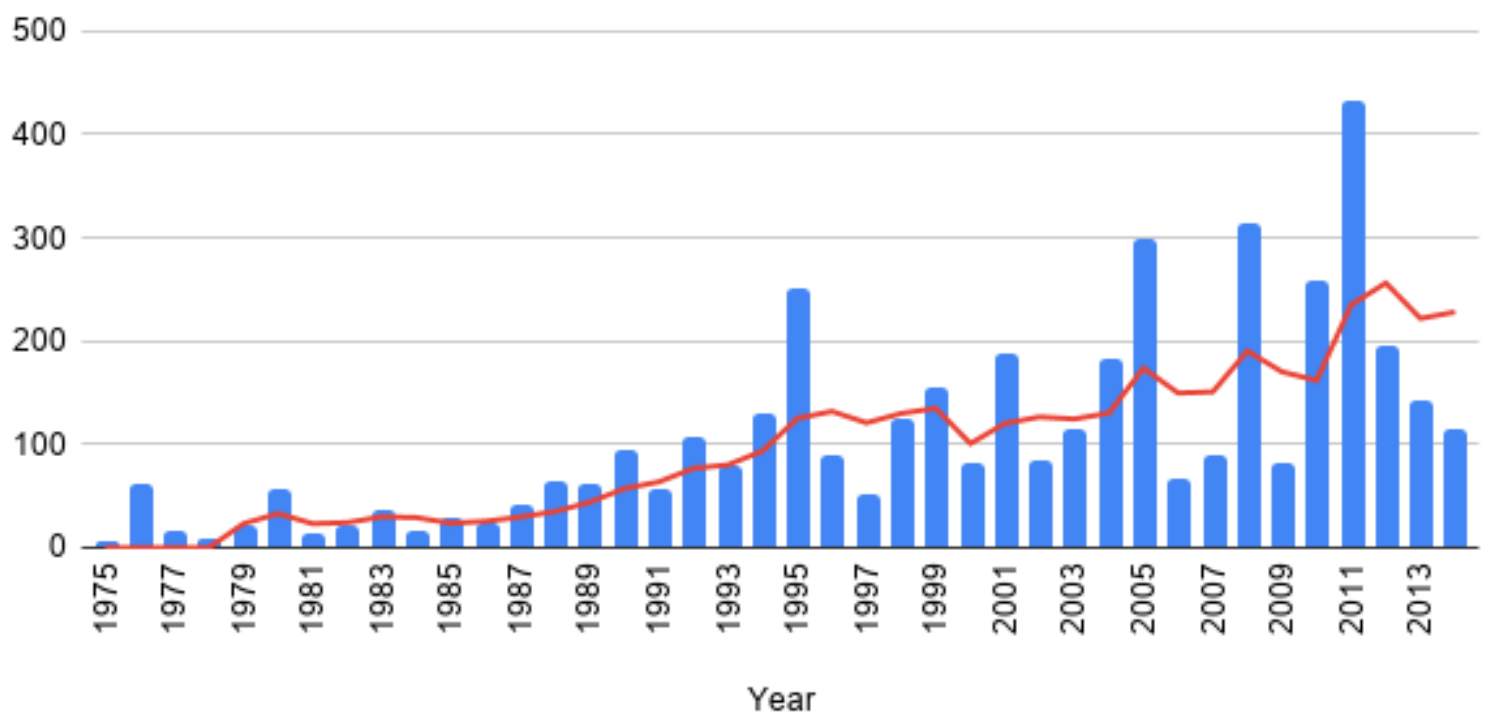

Figure 1: World-wide economic losses in billions of 2014 US\$ due to natural disasters, insured and uninsured, with their five-year moving average (Holzheu, 2015). (Note that world GDP during this period has grown around 3\% per year, which is much lower than the trend line above; World Bank, 2020.)

Another category of indirect argument for the increasing severity of weather comes from the theory of anthropogenic global warming itself. AGW implies a long-term shift in weather as the world heats, which in turn implies a succession of "new normals" - more extreme weather becoming normal until even more extreme weather replaces that norm - and hence a greater frequency of extreme weather events from the point of view of the old normal. In other words, everything that supports AGW, from validated general circulation models (GCMs) to observations, supports a general case that a variety of weather extremes is growing in frequency, intensity or both.

\section{Is Anthropogenic Global Warming Real?}

So, AGW implies an increase in many kinds of extreme weather; hence evidence for AGW also amounts to evidence that increases in extreme weather are real. That raises the question of AGW and the evidence for it. This article isn't the best place to address this issue, so l'd simply like to remind people of a few basic points, in case, for example, you're talking with someone rational:

- Skepticism and denialism are not the same. Skeptics test claims to knowledge; denialists deny them. No (living) philosophical skeptic, for example, would refuse to look around before attempting to cross a busy road.

- Science lives and breathes by skeptical challenges to received opinions. That's 
not the same as holding all scientific propositions in equal contempt. Our technical civilization - almost everything about it - was generated by applying established science. It is not activists who are hypocrites for using trains, the internet and cars to spread their message; the hypocrites are those who use the same technology, but deny the science behind that technology.

- Denialism requires adopting the belief that thousands of scientists from around the world are conspiring together to perpetrate a lie upon the public. David Grimes has an interesting probabilistic analysis of the longevity of unrevealed conspiracies (in which insiders have not blabbed about it), estimating that a climate conspiracy of this kind would require about 400,000 participants and its probability of enduring beyond a year or two is essentially zero [Grimes, 2016]. The lack of an insider revealing such a conspiracy is compelling evidence that there is no such conspiracy, in other words.

\section{The Detection of Extreme Weather}

The first issue to consider here is what to count as extreme weather - effectively a "Detection Problem" of distinguishing the "signal" of climate change from the "noise" of natural variation. The usual answer is to identify some probability threshold such that a kind of event having that probability on the assumption of a "null hypothesis" of natural variation would count as extreme. Different researchers will identify different thresholds. We might take, for example, a $1 \%$ chance of occurrence in a time interval under "natural" conditions as a threshold (which is not quite the same as a 1-in-100 interval event, by the way). "Natural" here needs to mean the conditions which would prevail were AGW not happening; ordinarily the average pre-industrial climate is taken as describing those conditions, since the few hundred years since then is too short a time period for natural processes to have changed earth's climate much, going on historical observations (chapter 4, Houghton, 2009). The cycle of ice ages works, for example, on periods of tens of thousands of years.

Of course, a one percent event will happen eventually. But the additional idea here, which I elaborate upon below, is to compare the probability of an event happening under the assumption of natural variation to its probability assuming anthropogenic global warming. The latter probability I will write $P(E I A G W)$ - the probability of event $E$ assuming that AGW is known to be true; the former I will write $P(E I \neg A G W)$ - the probability of $E$ assuming that AGW is known to be false. These kinds of probabilities (of events given some hypothesis) are called likelihoods in statistics. The likelihood ratio of interest is $P(E \mid \neg A G W) / P(E I A G W)$; the extent to which this ratio falls short of 1 (assuming it does) is the extent to which the occurrence of the extreme event supports the anthropogenic global warming hypothesis versus the alternative no warming (natural variation only) hypothesis. (The inverse ratio is also known as "relative risk" in, e.g., epidemiology, where analogous attribution studies are done.) A single such event may not make much of a difference to our opinion about global warming, but a glut of them, which is what we have seen over the decades, leaves adherence to a non-warming world hypothesis simply a manifestation of irrationality. As 
scientists are not, for the most part, irrational, that is exactly why the scientific consensus on global warming is so strong.

\section{Varieties of Extreme Weather}

There is a large variety of types of extreme weather which appear likely to have been the result of global warming. A recent IPCC study found the following changes at the global scale likely to very likely to have been caused by AGW: increases in the length and frequency of heat waves, increases in surface temperature extremes (both high and low), increased frequency of floods. They express low confidence in observed increases in the intensity of tropical cyclones - which does not mean that they don't believe it, but that the evidence, while supporting the claim, is not sufficiently compelling. On the other hand, there is no evidence for increased frequency of cyclones (Seneviratne et al., 2017). They don't address other extremes, but the frequency (return period) and intensity of droughts, increases in ocean extreme temperatures, and increases in mean land and ocean temperatures have elsewhere been attributed to AGW (some references below).

In addition to measurements of extreme events, there is some theoretical basis for predicting their greater occurrence. For example, changes to ocean temperatures, and especially ice melt changing the density of water in the Arctic, are known to affect ocean currents, which, depending upon the degree of change, will have likely affects on weather patterns (e.g., NOAA, 2019). Again, warmer air is well known to hold more water vapor, leading to larger precipitation events, resulting in more floods (Coumou and Ramstorf, 2012). Warmer water feeds cyclonic storms, likely increasing their intensity, if not their frequency (e.g., Zielinski, 2015).

\section{Causal Attribution Theory}

If we can agree that detection has occurred - that is, that weather extremes are increasing beyond what background variability would explain - then we need to move on to attribution, explaining that increase. There will always be some claiming that individual events that are "merely" probabilistically related to causes can never be explained in terms of those causes. For example, insurers and manufacturers and their spokespersons can often be heard to say such things as that, while asbestos (smoking, etc.) causes cancer - raising its probability this individual case of cancer could never be safely attributed to the proposed cause. This stance is contradicted by both the theory and practice of causal attribution.

What is Causation?

The traditional philosophy of causation, going back arguably to Aristotle and certainly to David Hume, was a deterministic theory that attempted to find necessary and sufficient conditions for one event to be a cause of another. That analytic approach to philosophy was itself exemplified in Plato's Socratic dialogues, which, ironically, were mostly dialogues showing the futility of trying to capture concepts in a tight set of necessary and sufficient conditions. Nevertheless, determinism dominated both philosophy and society at large for many centuries. It took until the rise of probabilistic theories within science, and especially 
that of quantum theory, before a deterministic understanding of causality began to lose its grip, first to the wholly philosophical movement of "probabilistic causality" and subsequently the development of probabilistic artificial intelligence - Bayesian network technology - which subsumed probabilistic causal theories and applied computational modeling approaches to the philosophical theory of causality. Formal probabilistic theories of causal attribution have flowed out of this research. The defences of inaction or a refusal to pay out insurance reliant upon deterministic causality are at least a century out of date.

Describing the interventionist theory of causality based upon Bayesian network models is beyond my scope here. (If you are interested, see Judea Pearl's Causality, James Woodward's Making Things Happen, or my own [Handfield, Twardy, Korb and Oppy's] "The Metaphysics of Causal Models," Erkenntnis.)

Instead I will describe an accepted theory of causal attribution in climate science, which provides a clear criterion for ascribing extreme weather events to AGW.

\section{Attribution Theory}

The most widely used attribution method for extreme weather is the Fraction of Attributable Risk (FAR) for ascribing a portion of the responsibility of an event to AGW (Stott et al., 2004). It has a clear interpretation and justification, and it has the advantage of presenting attribution as a percentage of responsibility, similar to percentages of explained variation in statistics (as Sewall Wright, 1934, pioneered). That is, it can apportion, e.g., 80\% of the responsibility of a flooding event to $A G W$ and $20 \%$ to natural variation ( $\neg A G W$ ) in some particular case, which makes intuitive sense. So, I will primarily discuss FAR in reference to attributing specific events to AGW. It should be borne in mind, however, that there are alternative attribution methods with good claims to validity (including my own, currently in development, based upon Korb et al., 2011), as well as some criticism of FAR in the scientific literature. The methodological science of causal attribution is not as settled as the science of global warming more generally, but is clear enough to support the claims of climate scientists that extreme weather is increasing due to climate change and in many individual cases can be directly attributed to that climate change.

FAR compares the probability of an extreme event $E$ under AGW - i.e., P(EIAGW) - and under a "null hypothesis" of no global warming (the negation of AGW, i.e., $\neg A G W$ ), by taking their ratio in:

$$
F A R=1-P(E / \neg A G W) / P(E I A G W)
$$

As is common in statistics, $E$ is taken as the set of events of a certain extremity or greater. For example, if there is a day in some region, say Sydney, Australia, with a high temperature of 48.9 , then $E$ would be the set of days with highs $\geq 48.9$.

Assuming there are no "acts of god", any event can be $100 \%$ attributed to prior causes; that is, the maximum proportion of risk that could possibly be explained is 1 . FAR splits that attribution into two parts, that reflecting $A G W$ and that reflecting everything else, i.e., natural variation in a pre-industrial climate (e.g., Schaller et al., 2016); it does so by subtracting from 
the maximum 1 that proportion that can fairly be allocated to the null hypothesis. To take a simple example (see Figure 2), suppose we are talking about an event with a $1 \%$ chance, assuming no $A G W$; i.e., $P(E I \neg A G W)=0.01$. Suppose that in fact $A G W$ has raised the chances ten-fold; that is, $P(E \mid A G W)=0.1$. Then the proportion $F A R$ attributes to the null hypothesis is $0.01 / 0.1=0.1$, and the fraction FAR attributes to AGW is the remainder, namely 0.9 . Since AGW has raised the probability of events of this particular extremity - of E's kind -10 fold, it indeed seems fair to attribute $10 \%$ of the causation to natural variation and $90 \%$ to unnatural variation.

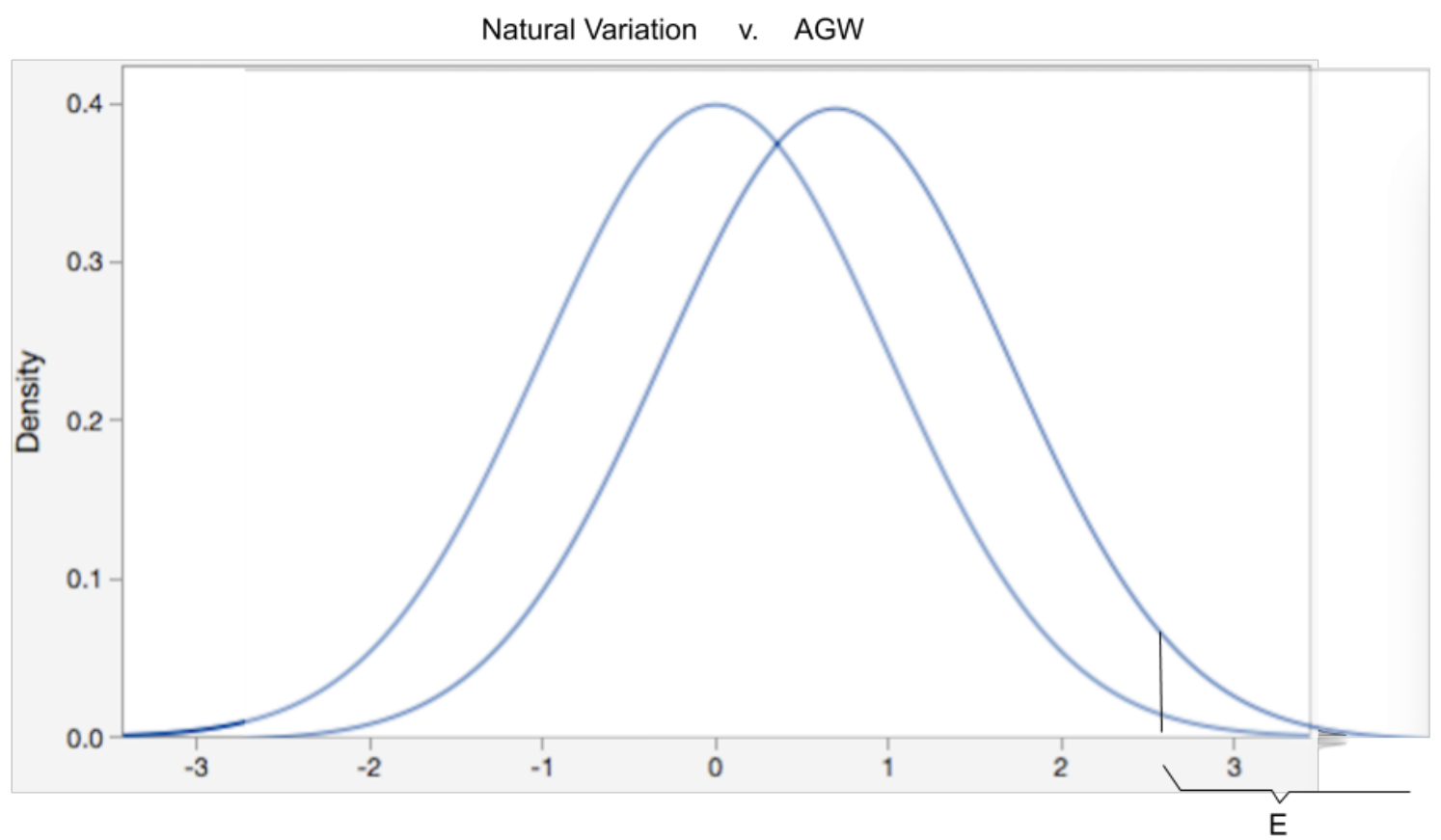

Figure 2. The region (event) $\mathrm{E}$ on the right shows where the natural distribution of weather (e.g., temperature) has no more than a $1 \%$ chance of producing that extreme an event, as determined by the left distribution. If AGW shifts the distribution to the right as in the figure, this extreme an event is 10 times more likely; that is, the area under the distribution to the right of the line is $10 \%$, rather than $1 \%$.

In order to compute FAR, we first need these probabilities of the extreme event. It's natural to wonder where they come from, since we are talking about extreme events, and thus unlikely events that we wouldn't have had the time and opportunity to measure. (To be sure, if good statistics have been collected historically, they may be used, especially for estimating $P(E I \neg A G W)$; some studies cited below have done that.) In fact, however, these likelihoods are derivable from the theories themselves, or simulations that represent such theories. GCMs are used to model anthropogenic global warming scenarios with different assumptions about the extent to which human economic behavior changes in the future, or fails to change. If we are interested in current extreme events, we can use such a model without any of the future scenarios: sampling the GCM model for the present will tell us how likely events of type $E$ will be under current circumstances, with AGW. But we can also use the model to estimate $P(E I \neg A G W)$ by running it without the past human history of climate forcing, to see how likely $E$ would be without humanity's contributions. Since the GCMs are well validated, this is a perfectly good way to obtain the necessary likelihoods. (However, 
some caveats are raised below.)

Since individual weather events occur in specific locations, or at least specific regions, in order to best estimate the probabilities of such events, GCMs are typically used in combination with regional weather models, which can achieve greater resolutions than GCMs alone. (GCMs can also be modified to have finer resolutions over a particular region.) Regional models have been improving more rapidly than GCMs in recent years, which is one reason that FAR attributions are becoming both more accurate and more common (e.g., Black et al., 2016).

\section{Attribution of Individual Weather Events}

Thus, there is a growing body of work attributing specific extreme weather events to anthropogenic global warming using FAR, which represents the "fraction" of responsibility that an event of the given extremity, or greater, can be attributed to anthropogenic global warming versus natural variation in a pre-industrial climate. Much of this work is being coordinated and publicized by the World Weather Attribution organization, which is a consortium of research organizations around the world.

I note some recent examples of FAR attributions (with confidence intervals for the estimates when reported up front). I do not intend to explain these specific attributions here; you can follow the links, which lead to summary reports explaining them. Those summaries cite the formal academic publications, which detail the methods and simulations used and the relevant statistics concerning the results.

- Flooding from tropical storm Imelda in September, 2019: FAR of $0.505( \pm 0.12)$ (World Weather Attribution, 2019). [Note: This was not reported as FAR, but in likelihoods; conversion to FAR is straightforward. Links are to specific reports, which themselves link to academic publications.]

- Heatwave in Germany and the UK, July, 2019: FAR between 0.67 and 0.9. The FAR for other parts of Europe were higher (but not specified in their summary) (World Weather Attribution, 2019).

- Heatwave in France, June, 2019: FAR about 0.9 (World Weather Attribution, 2019).

- Extreme rainfall from UK storm Desmond, December, 2017: FAR of about 0.375 (World Weather Attribution, 2019).

- Drought in the Western Cape of South Africa from 2015-2017, leading to a potential "Day Zero" for Cape Town, when the water would run out (averted by rainfall in June, 2018). This extreme drought had an estimated FAR of about 0.67 (World Weather Attribution, 2019).

- Extreme rainfall events in New Zealand from 2007-2017: FARs ranging from 0.10 to 0.40 ( \pm 0.20 in each case). These fractions accounted for NZ\$140.5M in insured costs, which was computed by multiplying the FARs with actual recorded costs (Noy, 2019). [NB: uninsured and non-dollar costs are ignored.] The application of FARs to 
compute responsibility for insurance costs by economists is a new initiative.

- The 2016 marine heatwave that caused severe bleaching of the Great Barrier Reef was estimated to have a FAR of about 0.95 for maximum temperature and about 0.99 for duration of the heatwave by Oliver et al. (2018). Their report is part of an (approximately) annual report in the Bulletin of the American Meteorological Society that reports on a prior year's extreme weather events attributable to human factors, the latest of which is Herring et al. (2018), a collection of thirty reports on events of 2016.

A recent review - re-examining FAR calculations via new simulations - of three dozen studies of droughts, heat waves, cold waves and precipitation events found numerous substantial FARs, ranging up to 0.99 in many cases, as well as a few with inverted FARs, indicating some events made less likely by anthropogenic global warming (Angélil et al., 2017).

The recent fires in Australia are being given a FAR analysis as I write this (see https://www.worldweatherattribution.org/bushfires-in-australia-2019-2020/). There is widespread agreement that the intensity of wildfires is increasing, and that the fire seasons in which they take place are lengthening. Fire simulation models capable of incorporating the observed consequences of climate change (droughts, heatwaves, etc.) are in use and can be applied to this kind of estimation, although that is not yet being done. The forthcoming analysis is limited to the precursors of the fires, drought and heat, but also including the Forest fire Weather Index (from a personal communication).

Despite the apparent precision of some of these FAR estimates, they all come with confidence intervals, i.e., ranges within which we would expect to find the true value. They are not all recorded above, but those who wish to find them can go to the original sources.

Another kind of uncertainty applies to these estimates, concerning the variations in the distributions used to estimate FARs such as those of Figure 2. Some suggest that AGW itself brings a greater variation in the weather, fattening the tails of any probability distribution over weather events, and so making extremes on both sides more likely. So, for example Figure 2 might more properly show a flatter (fatter) distribution associated with $\neg A G W$, in addition to being shifted to the right of the distribution for AGW. This, however, would not affect the appropriateness of a FAR estimation: whether the likelihood ratio for $E$ is determined by a shift in mean, a change in the tails, or both, that ratio nevertheless correctly reports the probabilities of the observed weather event relative to each alternative.

A potentially more pointed criticism is that GCMs may be more variable than the real weather (e.g., Osborn, 2004). Higher variability implies reaching extremes more often (on both ends of the scale). This is exacerbated if using multiple GCMs in an ensemble prediction. Such increased variance may apply more to simulations of AGW than to $\neg A G W$, although that's unclear. In any case, this is a fair criticism and suggests somewhat greater uncertainty in FAR attributions than may have been reported. It would be best addressed by improved validation of GCMs, whether individually or in ensemble. The science of weather attribution is relatively new and not entirely settled; nevertheless, the methods and results in qualitative terms are well tested and clear. Many individual extreme weather events can be 
attributed largely to human-induced climate change.

\section{The Future of Extreme Weather}

The future of extreme weather appears to be spectacular. Given the overwhelming scientific evidence for the existence and continued development of anthropogenic global warming, and the clear evidence of tepid commitment or positive opposition to action from political leaders around the world, climate change is not just baked in for the next few decades, but is likely to be accelerating during that time. The baking period will be the few hundred years thereafter. Extreme pessimism, however, should be discouraged. It really does matter just when, and how, national, regional and global activities to reduce or reverse greenhouse gas emissions are undertaken. Our choices could well determine whether we face only severe difficulties, or instead global chaos, or perhaps civilizational collapse, or even human extinction. It is certain that earth's biosphere will recover to some equilibrium eventually; it's not so certain whether that equilibrium will include us.

For the short term, at least, climate science will continue to make progress, including improved understanding of weather attribution. Our current understanding is already good enough to give strong support to the case for action, as put in a recent excellent review of the state of the art in weather attribution circa 2015 or so:

Event attribution studies ... have shown clear evidence for human influence having increased the probability of many extremely warm seasonal temperatures and reduced the probability of extremely cold seasonal temperatures in many parts of the world. The evidence for human influence on the probability of extreme precipitation events, droughts, and storms is more mixed. (Stott et al., 2016)

As l've shown above, since that review, attribution research has been extended to show considerable human influence on many cases of extreme rainfall, droughts and storms. While uncertainties remain, as regional and dynamic circulation models continue to improve, it seems certain that extreme weather attributions to anthropogenic causes will become both more pervasive and more definite in the near future. These improvements will enable us to better target our efforts at adaptation, as well as better understand the moral and legal responsibility for the damage done by unabated emissions.

Despite well-funded and entrenched opposition, we must push ahead with parallel projects to reduce, reverse and adapt to the drivers of climate change, in order to minimize the damage to our heirs, as well as to our future selves.

\section{Acknowledgements}

I would like to acknowledge the helpful comments of Steven Mascaro, Erik P Nyberg, Bruce Marcot, Lloyd Allison and anonymous reviewers to earlier versions of this article.

\section{References}


Allen, M. (2003). Liability for climate change. Nature, 421(6926), 891.

Angélil, O., Stone, D., Wehner, M., Paciorek, C. J., Krishnan, H. and Collins, W. (2017). An independent assessment of anthropogenic attribution statements for recent extreme temperature and rainfall events. Journal of Climate, 30, 5-16, doi:10.1175/JCLI-D-16$\underline{0077.1 .}$.

Bindoff, N.L., Stott, P.A., AchutaRao, K.M.,, Allen, M.R., Gillett, N.G., Gutzler, D., Hansingo, K., Hegerl, G., Hu, Y., Jain, S., Mokhov, I.I., Overland, J., Perlwitz, J., Sebbari, R., \& Zhang, $X$. (2013). Detection and attribution of climate change: from global to regional climate.

Climate Change 2013 The Physical Science Basis: Working Group I Contribution to the Fifth Assessment Report of the Intergovernmental Panel on Climate Change. T. Stocker, D Qin, Plattner G-K et al. Cambridge, UK, Cambridge University Press: 867-952.

Black, M. T., Karoly, D. J., Rosier, S. M., Dean, S. M., King, A. D., Massey, N. R., .. \& Otto, F. E. (2016). The weather@ home regional climate modelling project for Australia and New Zealand. Geoscientific Model Development, 9(9).

Climate Central (2019). The 10 Hottest Global Years on Record, 6 Feb, 2019.

https://www.climatecentral.org/gallery/graphics/the-10-hottest-global-years-on-record

Climate Nexus (2019). Record High Temps vs. Record Low Temps.

https://www.climatesignals.org/data/record-high-temps-vs-record-low-temps, accessed 6 Dec, 2019.

Colman, Z (2019). The new science fossil fuel companies fear. Politico, 22 Oct 2019. https://www.politico.com/agenda/story/2019/10/22/attribution-science-fossil-fuels-climatechange-001290

Coumou, D., \& Rahmstorf, S. (2012). A decade of weather extremes. Nature climate change, 2(7), 491.

Faust, E. \& Steuer, M. (2019). Climate Change Increases Wildfire Risk in California, Munich Re. url: https://www.munichre.com/topics-online/en/climate-change-and-naturaldisasters/climate-change/climate-change-has-increased-wildfire-risk.html. Accessed $20 \mathrm{Nov}$ 2019.

Grimes, D. R. (2016). On the viability of conspiratorial beliefs. PloS one, 11(1), e0147905.

Handfield, T., Twardy, C. R., Korb, K. B., \& Oppy, G. (2008). The metaphysics of causal models. Erkenntnis, 68(2), 149-168.

Herring, S. C., Christidis, N., Hoell, A., Kossin, J. P., Schreck III, C. J., \& Stott, P. A. (2018). Explaining extreme events of 2016 from a climate perspective. Bulletin of the American Meteorological Society, 99(1), S1-S157.

Hoffman, A.J. (2018). Rising insurance costs may convince Americans that climate change risks are real. The Conversation, 22 Oct, 2018. https://theconversation.com/rising-insurancecosts-may-convince-americans-that-climate-change-risks-are-real-105192 
Holzheu, T (2015). Underinsurance of property risks: closing the gap. Swiss Re, Sigma No $\underline{5 / 2015}$.

Houghton, J. (2009). Global warming: the complete briefing. Cambridge University Press.

IPCC (2014). AR5 Climate Change 2014: Impacts, Adaptation, and Vulnerability.

Korb, K. B., Nyberg, E. P., \& Hope, L. (2011). A new causal power theory. Illari, Russo and Williamson (Eds) Causality in the Sciences, Oxford University Press, pp. 628-652.

McAneney, J., Sandercock, B., Crompton, R., Mortlock, T., Musulin, R., Pielke Jr, R., \& Gissing, A. (2019). Normalised insurance losses from Australian natural disasters: 19662017. Environmental Hazards, 1-20.

NOAA (2018). Global Climate Report --. Annual 2018. url:

https://www.ncdc.noaa.gov/sotc/global/201813. Accessed 20 Nov 2019.

NOAA (2019). How does sea ice affect global climate? National Ocean Service website, https://oceanservice.noaa.gov/facts/sea-ice-climate.html, 11/15/19.

Noy, I. (2019). The economic costs of extreme weather events caused by climate change. Australasian Bayesian Network Modelling Society Conference, Wellington, New Zealand, 13-14 November, 2019.

Oliver, E. C., Perkins-Kirkpatrick, S. E., Holbrook, N. J., \& Bindoff, N. L. (2018).

Anthropogenic and natural influences on record 2016 marine heat waves. Bulletin of the American Meteorological Society, 99(1), S44-S48.

O’Keeffe, L. M., Taylor, G., Huxley, R. R., Mitchell, P., Woodward, M., \& Peters, S. A. (2018). Smoking as a risk factor for lung cancer in women and men: a systematic review and meta-analysis. BMJ open, 8(10), https://bmjopen.bmj.com/content/8/10/e021611.

Osborn, T. J. (2004). Simulating the winter North Atlantic Oscillation: the roles of internal variability and greenhouse gas forcing. Climate Dynamics, 22(6-7), 605-623.

Pearl, J. (2000). Causality: Models, Reasoning and Inference. Cambridge: MIT Press.

Schaller, N., Kay, A. L., Lamb, R., Massey, N. R., Van Oldenborgh, G. J., Otto, F. E., Sparrow, S. N., Vautard, R., Yiou, P., Ashpole, I., Bowery, A., Crooks, S. M., Haustein, K., Huntingford, C., Ingram, W. J., Jones, R. G., Legg, T., Miller, J., Skeggs, J., Wallom, D., Weisheimer, A., Wilson, S., Stott, P. A., Allen, M. R. (2016). Human influence on climate in the 2014 southern England winter floods and their impacts. Nature Climate Change, 6(6), 627.

Seneviratne, S.I., N. Nicholls, D. Easterling, C.M. Goodess, S. Kanae, J. Kossin, Y. Luo, J. Marengo, K. Mclnnes, M. Rahimi, M. Reichstein, A. Sorteberg, C. Vera, and X. Zhang, 2012: Changes in climate extremes and their impacts on the natural physical environment. In:

Managing the Risks of Extreme Events and Disasters to Advance Climate Change Adaptation [Field, C.B., V. Barros, T.F. Stocker, D. Qin, D.J. Dokken, K.L. Ebi, M.D. Mastrandrea, K.J. Mach, G.-K. Plattner, S.K. Allen, M. Tignor, and P.M. Midgley (eds.)]. A 
Special Report of Working Groups I and II of the Intergovernmental Panel on Climate Change (IPCC). Cambridge University Press, Cambridge, UK, and New York, NY, USA, pp. 109-230.

Stott, P. A., Christidis, N., Otto, F. E., Sun, Y., Vanderlinden, J. P., Van Oldenborgh, G. J., ... \& Zwiers, F. W. (2016). Attribution of extreme weather and climate-related events. Wiley Interdisciplinary Reviews: Climate Change, 7(1), 23-41.

Stott, P. A., Stone, D. A., \& Allen, M. R. (2004). Human contribution to the European heatwave of 2003. Nature, 432(7017), 610.

US Global Change Research Program (2017). Climate Science Special Report: Fourth National Climate Assessment, Volume I [Wuebbles, D.J., D.W. Fahey, K.A. Hibbard, D.J. Dokken, B.C. Stewart, and T.K. Maycock (eds.)] doi: 10.7930/J0J964J6.

Wallace, C. S. (2005). Statistical and Inductive Inference by Minimum Message Length. Springer Verlag.

Woodward, J. (2005). Making Things Happen: A Theory of Causal Explanation. Oxford University Press.

World Bank (2010). Data, GDP annual growth.

https://data.worldbank.org/indicator/NY.GDP.MKTP.KD.ZG, accessed 18 Jan 2020.

World Weather Attribution (2019). World Weather Attribution.

http://www.worldweatherattribution.org/.

Wright, S. (1934). The method of path coefficients. The Annals of Mathematical Statistics, 5(3), 161-215.

Zielinski, S. (2015). Warmer Waters Are Making Pacific Typhoons Stronger. Smithsonian Magazine. 